This item was submitted to Loughborough's Research Repository by the author.

Items in Figshare are protected by copyright, with all rights reserved, unless otherwise indicated.

\title{
Effects of fuel composition on high-pressure non-premixed natural gas combustion
}

PLEASE CITE THE PUBLISHED VERSION

http://dx.doi.org/10.1080/00102200802612260

PUBLISHER

(c) Taylor \& Francis

VERSION

SMUR (Submitted Manuscript Under Review)

LICENCE

CC BY-NC-ND 4.0

\section{REPOSITORY RECORD}

McTaggart-Cowan, G.P., N. Wu, B. Jin, S.N. Rogak, Martin H. Davy, and W.K. Bushe. 2019. "Effects of Fuel Composition on High-pressure Non-premixed Natural Gas Combustion”. figshare.

https://hdl.handle.net/2134/4948. 
This item was submitted to Loughborough's Institutional Repository (https://dspace.lboro.ac.uk/) by the author and is made available under the following Creative Commons Licence conditions.

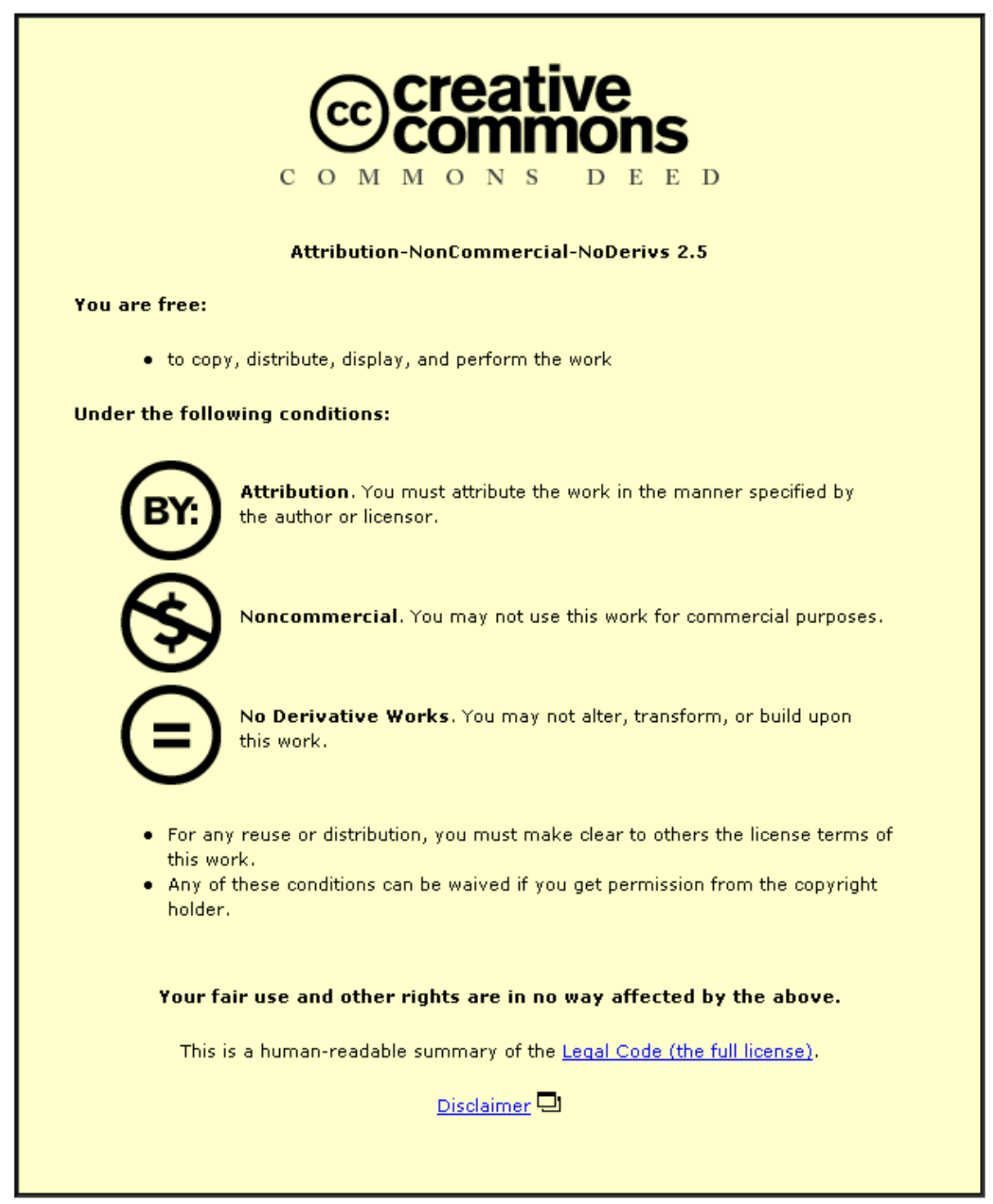

For the full text of this licence, please go to: http://creativecommons.org/licenses/by-nc-nd/2.5/ 
This is a preprint of an article whose final and definitive form has been published

in COMBUSTION SCIENCE AND TECHNOLOGY (C) 2009 [copyright Taylor \& Francis];

COMBUSTION SCIENCE AND TECHNOLOGY is available online at: http://www.informaworld.com with the article available from the open URL:

http://www.informaworld.com/openurl?genre=article\&issn=1563-521X\&volume=181\&issue=3\&spage=397

\title{
Effects of Fuel Composition on High-Pressure Non-Premixed Natural Gas Combustion
}

\author{
G.P. McTaggart-Cowan ${ }^{* 1}$, N. Wu², B. Jin ${ }^{2}$, S.N. Rogak ${ }^{2}$, M.H. Davy ${ }^{2}$ and W.K. Bushe ${ }^{2}$ \\ ${ }^{1}$ Wolfson School of Mechanical and Manufacturing Engineering, Loughborough University, UK \\ ${ }^{2}$ Department of Mechanical Engineering, University of British Columbia, Vancouver, Canada
}

\section{Abstract}

The effects of adding ethane or nitrogen on the ignition and combustion of a non-premixed highpressure methane-air jet have been investigated using fundamental studies in a shock tube and advanced computational modelling. The results are then used to interpret the performance of a pilot-ignited natural gas engine fuelled with similar fuels. The results show that the influence of the additives on the gaseous jet autoignition process is relatively small, but that they have a greater effect on the research engine, where both fuels have similar influences on the spatial relationship between the gaseous jet and the pilot flame.

Key Words: Non-premixed methane; natural gas composition; gaseous fuel dilution; pilot-ignition engine

\section{Introduction}

Heavy-duty engine manufacturers are developing advanced in-cylinder and post-exhaust aftertreatment devices to ensure that diesel engines meet stringent new emission standards. However, reducing the formation of these species, as well as any attempt to reduce carbon dioxide emissions, are limited by the properties of the liquid diesel fuel. Replacing the fuel with natural gas offers the potential to achieve substantial pollutant emission reductions, while making use of a widely-available and competitively priced alternative fuel. Most current in-use natural gas fuelled engines use premixed charge spark-ignition technology, which suffers from reduced efficiency and high emissions of unburned methane. New technologies that retain the diesel engine's direct-injection, compression ignition combustion process are under development. However, further understanding of the fundamentals of the high-pressure, turbulent, non-premixed natural gas combustion process is required to optimize the combustion system.

* Contact author: g.mctaggart-cowan@lboro.ac.uk. Wolfson School of Mechanical and Manufacturing Engineering, Loughborough University, Loughborough, UK. LE11 3TU. Phone: +44(0)1509227575 
One of the barriers facing wide-spread use of natural gas in transportation applications is variations in the fuel composition. Levels of heavy hydrocarbons (ethane, propane, etc.) and of diluents vary with the fuel source, time of year, and the requirements of the gas supplier. Unconventional gases, such as synthetic natural gas, may contain substantially larger quantities of these species (Richards et al. 2001). The presence of these species in the fuel may have a significant effect on the combustion process, particularly in the areas of ignition delay and pollutant formation. Diluting the fuel with an inert species should reduce the combustion temperature, thereby reducing the formation rate of nitric oxide (NO) through the thermal (Zeldovich) mechanism. However, it may also substantially influence the combustion event both by directly reducing fuel concentrations and indirectly by influencing the gaseous jet penetration and mixing rates. Adding a heavier hydrocarbon, such as ethane $\left(\mathrm{C}_{2} \mathrm{H}_{6}\right)$ to the fuel affects both the chemical properties of the fuel and the physical mixing and penetration of the gaseous jet.

The current work aims to improve understanding of the effects of adding either a diluent (nitrogen) or a reaction enhancer (ethane) to a gaseous fuel in a high-pressure non-premixed combustion event through the use of computational modelling and fundamental shock tube experiments. The findings are then used to interpret results from a research engine operating on direct-injected natural gas with varying ethane and nitrogen content in the fuel.

\section{Direct Injection Gaseous Combustion Systems}

In a typical diesel combustion process, the liquid auto-ignites in the high pressure and temperature environment of the combustion chamber just prior to the piston reaching the end of the compression stroke. The auto-ignition delay time for natural gas at these same conditions is unacceptably long and variable (Huang et al. 2004). To achieve non-premixed combustion of natural gas under the conditions typically found in a diesel engine, an ignition source is needed; options include spark or glow-plugs or the use of a diesel pilot injection. Pilot injection has the advantage of initiating combustion at multiple points centrally located in the combustion chamber, thereby being less sensitive to the spatial location of the natural gas jet.

One system which combines pilot ignition with direct-injection of natural gas is under development by Westport Innovations Inc. The system involves a dual-fuel injector, which first injects the diesel pilot fuel late in the compression stroke, followed after a brief delay by natural gas injected through separate holes. The diesel fuel auto-ignites, creating the conditions required for natural gas ignition to occur. Following an initial pre-mixed combustion of the natural gas which has mixed with air prior to ignition, the bulk of the 
natural gas is consumed in a non-premixed gaseous jet. The combustion system is described in more detail elsewhere (McTaggart-Cowan, 2006). While charge dilution significantly reduces oxides of nitrogen $\left(\mathrm{NO}_{\mathrm{x}}\right)$ emissions from this combustion system (Hill and McTaggart-Cowan, 2005), the effects of diluting the fuel in such a turbulent non-premixed combustion event are uncertain. Simultaneously, changes in the concentrations in heavier hydrocarbons in the fuel may have a significant impact on both the ignition and combustion events; the impact of these on a non-premixed combustion process in an engine is unknown.

\section{Effect of Nitrogen on Gaseous Fuel Combustion}

The effect of diluting a gaseous fuel with nitrogen has been investigated in various contexts. For a natural gas fuelled, premixed charge engine, Nellen and Boulouchos (2000) and Crookes et al. (2006) report that adding $\mathrm{N}_{2}$ to the fuel improves knock resistance but reduces efficiency at a constant fuel-air stoichiometry; the effects are generally equivalent to the use of exhaust gas recirculation (EGR) to dilute the charge. Fuel dilution in non-premixed combustion systems has not been as extensively investigated; Feese and Turns (1998) report that, in a low pressure non-premixed turbulent combustion system (an industrial boiler), fuel dilution reduces $\mathrm{NO}_{\mathrm{x}}$ emissions more effectively than does oxidizer dilution by enhancing postreaction mixing rates, resulting in more rapid quenching of the NO-forming reactions. The study suggests that the reaction-zone chemistry is insensitive to the source of the diluent.

Nitrogen is commonly used as a diluent in fundamental non-premixed combustion studies, primarily as a technique to reduce fuel concentrations. For a non-premixed opposed flow diffusion flame (Fotache et al. 1997), no significant effects are observed until the fuel stream contains more than $80 \% \mathrm{~N}_{2}$ (by volume). Gulder et al. (1995) report that in a co-flow laminar flame the soot volume fraction is reduced proportionally with the methane concentration; the authors do not identify any further effect of the nitrogen on soot formation or oxidation kinetics. These results indicate that the principal influence of nitrogen addition manifests itself by reducing the energy density of the fuel. There is no evidence of direct participation in the reaction kinetics, even at very high $\mathrm{N}_{2}$ concentrations.

One of the principal effects of nitrogen addition to the gaseous jet is reducing the energy density of the injected gas, resulting in a longer injection to provide the same amount of available chemical energy. Changing the density of the injected fuel will also influence the penetration distance and turbulent mixing of the gaseous jet. However, no attempt to evaluate the influence of nitrogen content on a high-pressure turbulent non-premixed methane jet flame has been reported in the literature to date. 


\section{Effect of Ethane on Gaseous Fuel Combustion}

For premixed charge combustion, the greatest influences of heavy hydrocarbons such as ethane on the combustion of natural gas are in the ignition and early combustion phases. The ignitability of the mixture is enhanced, due primarily to pre-combustion increases in the concentration of $\mathrm{H}, \mathrm{OH}$, and $\mathrm{HO}_{2}$ radicals from decomposition of the heavier hydrocarbons (Khalil and Karim, 2002; Nellen and Boulchos, 2000). The formation of hydrocarbon radicals, including $\mathrm{C}_{2}$ species such as the ethyl radical $\left(\mathrm{C}_{2} \mathrm{H}_{5}\right)$ and acetylene $\left(\mathrm{C}_{2} \mathrm{H}_{2}\right)$, is also enhanced, although formation of these hydrocarbons also occurs in reactions involving only pure methane, through recombination of the methyl $\left(\mathrm{CH}_{3}\right)$ radical (Hiltner et al. 2003). The importance of the $\mathrm{H}, \mathrm{O}$, and $\mathrm{HO}_{2}$ radicals appears primarily at higher temperatures; at low temperatures, significant formation of the methylperoxy $\left(\mathrm{CH}_{3} \mathrm{O}_{2} \mathrm{H}\right)$ radical by ethane decomposition appears to be the primary mechanism for enhanced ignition (Huang and Bushe, 2006). At higher temperatures (pre-combustion $T>1200 \mathrm{~K}$ ) the formation of $\mathrm{OH}$ from ethane appears to be the dominant ignition enhancing mechanism (Huang and Bushe, 2006). The fundamental and applied studies available from the literature generally agree that significant enhancement of the ignition process is achieved with ethane addition due to enhanced radical formation.

Similar to premixed combustion, the principal influence of ethane addition to a gaseous nonpremixed combustion event is also on the ignition process. At high temperatures $(>1400 \mathrm{~K})$ fuel additives have little effect as this process is mixing limited (Nellen and Boulchous, 2000). At lower temperatures, the addition of ethane reduces the ignition delay time by as much as $0.7 \mathrm{~ms}$. The shorter ignition delay time has also been identified as a potential source for increased $\mathrm{NO}_{\mathrm{x}}$ emissions with ethane addition to the fuel (Sullivan et al. 2005); however, substantially more work is required to understand the effects of both ethane and nitrogen addition to the ignition and pollutant formation mechanisms in a non-premixed combustion system that is applicable to pilot-ignited engine operating conditions.

\section{Experimental and Computational Information}

Two separate experimental facilities are combined with advanced modelling in this work to investigate the effects of fuel composition on non-premixed methane combustion. A shock tube facility with a gaseous fuel injection system provides improved understanding of the fundamental effects of $\mathrm{N}_{2}$ and $\mathrm{C}_{2} \mathrm{H}_{6}$ addition on non-premixed gaseous jet ignition and combustion. The results from the shock tube are compared to numerical simulations to provide a more comprehensive understanding of the fundamental effects of fuel composition on a non-premixed combustion event. A single-cylinder research engine provides 
indications of the implications of these findings on pollutant formation and combustion in a heavy-duty engine application. The experimental facilities and numerical procedures are described in detail elsewhere; only a brief overview of each is provided here, along with the details pertinent to comparisons between these three techniques. Three fuels were compared for all the techniques: the modelling and shock tube studies compared pure methane with methane blended with $20 \% \mathrm{~N}_{2}$ and $10 \% \mathrm{C}_{2} \mathrm{H}_{6}$ by volume. For the engine tests, the base fuel was natural gas $\left(>96 \% \mathrm{CH}_{4}\right)$, which was blended with either $20 \% \mathrm{~N}_{2}$ or $9.8 \% \mathrm{C}_{2} \mathrm{H}_{6}$.

\section{Shock Tube}

The shock tube used in this work has been described previously (Huang et al. 2004; Sullivan et al. 2005, 2006; Wu et al. 2007). The facility employs a reflected shock wave technique to preheat and compress the air just prior to injection of the gaseous fuel. Reflection of the shock wave from the test-section end wall generates a quiescent, high temperature region into which the fuel is injected. The stainless steel shock tube is $7.90 \mathrm{~m}$ long (3.11 $\mathrm{m}$ driver section and $4.79 \mathrm{~m}$ driven section) with an inside diameter of $5.9 \mathrm{~cm}$. Four flush-mounted dynamic pressure transducers measure the incident shock velocity. Using this velocity, the test region temperature and pressure (after the passing of the reflected shock) are determined by solving the 1-D conservation equations for mass, momentum, and energy across the shock wave. Ideal gas behaviour is assumed and temperature-dependent fluid thermal properties are accounted for. The uncertainties in the calculated temperature and pressure are about $1-2 \%$ and $3-4 \%$, respectively, as discussed elsewhere (Huang, 2000; Huang et al. 2004). The custom injector used in this work has a single nozzle $(0.275 \mathrm{~mm}$ diameter) aligned axially with the shock tube center line. There is no external ignition source.

\section{Combustion Event Monitoring}

The combustion event is monitored optically through quartz windows $(2 \mathrm{~cm} \times 20 \mathrm{~cm})$ in the combustion zone, as well as with high-speed pressure transducers. A high frame rate CMOS-based digital camera (Vision Research Phantom v7.1 equipped with a $50 \mathrm{~mm}$ F/1.2 Nikon lens) measures the natural flame luminosity as well as blackbody radiation from any particles in the shock tube. For this work, the camera was operated at a frame rate of approximately 31,000 frames/second with an effective integration time of $1 \mu \mathrm{s}$ per frame and a nominal imaging resolution of $0.2 \mathrm{~mm} \times 0.2 \mathrm{~mm}$ per pixel. The pixel sensitivity is approximately flat for light wavelengths from $400 \mathrm{~nm}$ to $700 \mathrm{~nm}$ with relatively sharp roll-offs at 400 and 800 $\mathrm{nm}$. Light imaged in these experiments was depth of field integrated. 
The timing and location of the ignition kernels are easily identified from the recorded images. For this study, an ignition kernel is defined as the emergence of a non-contiguous new flame region not generated by the propagation of an existing flame. The auto-ignition delay time is defined as the time from the start of fuel injection until the emergence of the first ignition kernel. The distance from the injector tip to the nearest (closest downstream) ignition kernel is defined as $Z_{k}$. To account for the variation in fuel mass flux with injector orifice diameter $(d)$ and fuel/oxidizer pressure ratio $\left(P_{i} / P_{o}\right)$, we normalize $Z_{k}$ by:

$$
Z_{k}^{*}=Z_{k} / d^{*}, \text { where } d^{*}=d \sqrt{P_{i} / P_{o}},
$$

as discussed by Hill and Ouellette (1999) and Rubas et al. (1998).

\section{$\mathrm{NO}_{\mathrm{x}}$ Emissions}

An API 200E Chemiluminescent $\mathrm{NO}_{x}$ analyzer measures total $\mathrm{NO}_{\mathrm{x}}\left(\mathrm{NO}+\mathrm{NO}_{2}\right)$. After each experiment, the pressurized contents of the shock tube are discharged into a large $(400 \mathrm{~L})$ sampling bag constructed from electrically conducting carbon-impregnated polyolefin. The $\mathrm{NO}_{\mathrm{x}}$ analyzer then extracts a sample from the bag for analysis.

\section{Shock Tube Test Conditions}

Two sets of tests were conducted in the shock tube for each fuel composition, as summarized in Table 1. For all the results presented here, the pre-combustion pressure, $P_{0}$, was fixed at 30 bar, while the commanded injection duration was fixed at $1.0 \mathrm{~ms}$. Initially, 20 repeat experiments were performed at a precombustion temperature $\left(T_{0}\right)$ of $1300 \mathrm{~K}$ and an injection pressure $\left(P_{i}\right)$ of 120 bar to more fully study run-torun variability. Subsequently $T_{0}$ was varied between 1200 and $1400 \mathrm{~K}$ at constant injection pressure. At least 3 replications were carried out for each condition for each fuel blend. The total number of tests $(n)$ conducted with each fuel are also shown in Table 1.

Table 1. Operating conditions and sample size for shock tube experiments

\begin{tabular}{|l|l|l|l|l|l|l|}
\hline Exp Series & $\mathrm{P}_{\mathrm{o}}($ bar $)$ & $\mathrm{T}_{\mathrm{o}}(\mathrm{K})$ & $\mathrm{P}_{\mathrm{i}}($ bar $)$ & $\mathrm{n}\left(\mathrm{CH}_{4}\right)$ & $\mathrm{n}\left(20 \% \mathrm{~N}_{2}\right)$ & $\mathrm{n}\left(10 \% \mathrm{C}_{2} \mathrm{H}_{6}\right)$ \\
\hline Repeated & 30 & 1300 & 120 & 20 & 20 & 20 \\
\hline Effect of $\mathrm{T}_{\mathrm{o}}$ & 30 & $1200-1400$ & 120 & 16 & 14 & 13 \\
\hline
\end{tabular}

\section{Numerical Simulation}

The modelling work reported here uses Reynolds-Averaged Navier Stokes (RANS) simulation of the reacting flow-field, executed using OpenFOAM (OpenFOAM, nd). Conditional Source-term Estimation (CSE) is used to obtain chemical closure, while a Trajectory Generated Low-Dimensional Manifold (TGLDM) method is used to reduce the chemical mechanism to a tractable size. The following provides a brief 
overview of the modelling techniques used here: a more detailed description of the processes is available elsewhere (Jin, 2007; Huang and Bushe, 2007).

RANS modelling obtains a representation of the flow-field by decomposing each parameter into a mean and a randomly fluctuating component. Density weighted (Favre) averaging is used to avoid the appearance of unclosed terms involving density fluctuations. The RANS equations for reacting flows contain mean chemical source-terms which must be closed. To obtain closure in this work, we use CSE, which solves an integral equation to approximate conditional averages of reactive scalars, then invokes a first conditional moment closure assumption, such as is often used in Conditional Moment Closure methods (Klimenko and Bilger, 1999). Further details about CSE and its use in similar simulations can be found elsewhere (Bushe and Steiner 1999; Steiner and Bushe, 2001; Jin, 2007).

The complex chemistry of a non-premixed methane-air reaction is too complicated to be solved in a reasonable time-frame; as a result, a reduced mechanism needs to be generated. The technique used here to generate the reduced mechanism is TGLDM, which has been successfully combined with CSE in previous work (Huang and Bushe, 2007; Wang et al. 2006). The TGLDM technique is based on the low dimensional manifold concept first proposed by Maas and Pope (1992). The method takes advantage of the fact that the reactions in a chemical process occur over a wide range of time scales. Fast processes attenuate quickly; a reaction system will converge onto manifolds of fewer dimensions on the longer time-scales relevant to reactions such as in a turbulent non-premixed flame. The TGLDM method is used to find the manifold, which is parameterized by progress variables such as species concentration and temperature. TGLDM manifolds can be calculated and tabulated in pre-processing and retrieved later during a combustion simulation; they thus significantly reduce computational burden.

\section{Engine}

To complement the fundamental results established from the shock tube testing and computational modelling, a series of tests were conducted on a single-cylinder research engine equipped with a prototype direct-injection of natural gas combustion system. The engine used is a Cummins ISX series heavy-duty engine modified for single cylinder operation (Table 2); the experimental facility has been described in detail previously (McTaggart-Cowan et al. 2003, McTaggart-Cowan 2006). The diesel and natural gas injection processes are controlled electronically using a single multi-fuel injector. The engine is also equipped with a 
custom air-exchange system to ensure that the charge conditions are independent of variations in fuel composition and injection timing.

Table 2: Engine and Injector Specifications

\begin{tabular}{|l|l|}
\hline Engine & Cummins single cylinder 4-stroke, 4-valve \\
\hline Fuelling & Direct injection; diesel pilot, gaseous main fuel \\
\hline Displacement (/cylinder) & $2.5 \mathrm{~L}$ \\
\hline Compression Ratio & $17: 1$ \\
\hline Injector & Westport Innovations Inc. dual-fuel concentric needle \\
\hline \multicolumn{1}{|c|}{ Injection control } & Separate diesel and natural gas solenoids \\
\hline \multicolumn{1}{|l|}{ Injector holes } & 7 pilot, 9 gas \\
\hline Injection angle & $18^{\circ}$ below fire deck \\
\hline
\end{tabular}

The engine facility is fully instrumented, with measurements of air and fuel flow (both diesel pilot and

natural gas) as well as exhaust gas composition. The gaseous fuel flow measurement uses a coriolis-force mass flow sensor, and hence is insensitive to changes in gaseous fuel composition. The combustion process is monitored using a high-speed water cooled in-cylinder pressure transducer in conjunction with a $12^{\circ}$ crankangle encoder to identify the piston location. The heat-release rate (HRR) can be calculated from this information (Heywood, 1988):

$$
\frac{d Q_{n e t}}{d \theta}=\frac{\gamma}{\gamma-1} p \frac{d V}{d \theta}+\frac{1}{\gamma-1} V \frac{d p}{d \theta}
$$

where $\theta$ is the crank angle (CA), $p$ is the in-cylinder pressure and $V$ the cylinder volume at a specific crankangle, and $\gamma$ is the specific heat ratio (assumed constant). The net HRR represents the rate of energy release from the combustion processes less wall heat transfer and crevice flow losses. Using the integral of the HRR as a function of CA (integrated heat release, IHR) provides the duration (in crank angles) for a given fraction of the total energy to be released. In this work, we identify start-of-combustion timing and combustion duration using the average HRR based on 50 consecutive cycles is used. The cycle-to-cycle variability in the combustion is ascertained by evaluating the heat-release rate for the same 50 cycles individually. The $10 \%$ IHR point (when $10 \%$ of the total energy has been released) is used to provide a quantifiable and repeatable indication of the start-of-combustion for the gaseous fuel. While this does not necessarily coincide exactly with the gaseous fuel start-of-combustion, the trends with combustion timing and fuel composition should be consistent between start-of-combustion and the $10 \%$ IHR point.

\section{Engine Test Conditions}

The engine testing was conducted at a condition that provided combustion conditions similar to those encountered under mid-speed, $75 \%$ load conditions. Running the engine with a charge dilution (mass 
of recirculated exhaust / total charge mass) of $30 \%$ generates relatively low $\mathrm{NO}_{\mathrm{x}}$ levels without excessively degrading the combustion event. The injection pressure was held constant at 310 bar; the in-cylinder pressure at the start-of-injection varied with injection timing, but was on the order of $70-100$ bar, generating pressure ratios similar to those in the shock tube (3-4.5:1). Varying the timing of the combustion (controlled by the start-of-injection timing of the diesel; the gaseous fuel injection started a fixed $1.0 \mathrm{~ms}$ after the end of the diesel injection) provided a range of combustion conditions while maintaining constant charge composition and overall fuel-air equivalence ratio $(\phi)$. Four timings were used in this work, with the later timings corresponding to higher in-cylinder temperatures and pressures during the injection and ignition processes. For all conditions, the energy content of the injected fuel was held constant, with the injection duration being varied to account for changes in fuel energy content. The pilot diesel quantity was fixed at $5 \%$ of the total on an energy basis. For each test condition, at least three independent replications were carried out; error analysis was conducted using 95\% confidence intervals $(\mathrm{Cl})$ around the mean of these values.

\section{Non-premixed gaseous combustion}

Before discussing the experimental results, it is useful to review similarities and differences between the combustion systems. The oxidizer in the shock tube is quiescent, with constant temperature and pressure. Conversely, the charge in the engine is highly turbulent, including local high-intensity turbulence induced by the gas jet, as well as bulk motion (swirl and tumble) induced by the induction and in-cylinder flow processes. The temperature and pressure of the charge vary as the piston moves; however, this is a minor effect in the region of interest, as the piston motion around top-dead-center is relatively small (the piston moves only $4 \%$ of the total stroke length over the $20^{\circ}$ before or after TDC).

The ignition method also differs: in the shock tube, the gaseous fuel auto-ignites in the relatively high temperature environment, while a diesel pilot flame promotes ignition in the engine. Whether the pilot flame simply provides heat to enhance reaction rates, or also supplies a pool of radicals to help the ignition, is unclear. The presence of the diesel pilot makes the natural gas ignition event more sensitive to spatial location; this could result in ignition occurring in different zones of the gas jet from where a pure auto-ignition event would occur.

These differences suggest that there may be significant variation in the effects of gaseous fuel composition between the two combustion systems. However, by identifying both the similarities and the differences between them, it is possible to develop a greater understanding of the effects of nitrogen and 
ethane addition on a non-premixed natural gas jet than could be developed from studying either combustion system individually.

\section{RESULTS}

In this work, we will present the results from the shock tube study first, followed by the numerical results. The computational modelling was conducted to evaluate conditions equivalent to those in the shock tube. The simulation results provide a higher level of understanding of how a transient jet combustion process is influenced by fuel composition. The increased understanding generated from these studies can then be used to provide a more in-depth analysis of the fundament influences affecting the performance and emissions of an engine operating on non-premixed combustion of directly-injected natural gas.

\section{SHOCK TUBE RESULTS}

The fuels tested in the shock tube were pure methane, methane blended with $20 \% \mathrm{~N}_{2}$ and methane blended with $10 \% \mathrm{C}_{2} \mathrm{H}_{6}$. The shock tube results are presented in terms of the effect of ethane and nitrogen addition on the ignition delay period, the ignition kernel location, and $\mathrm{NO}_{\mathrm{x}}$ emissions, as a function of precombustion temperature. The following provides the most pertinent aspects of the results: more details can be found elsewhere (Wu, 2007).

\section{Ignition Delay}

The effect of both ethane and nitrogen addition are shown in Table 3 for the repeated case (20 replications of each fuel blend at fixed $T_{\circ}$ and $\left.P_{o}\right)$. Error in the ignition delay $\left(t_{d}\right.$ ign $)$ is estimated at $(+0.106$ $\mathrm{ms},-0.073 \mathrm{~ms})$, attributed to uncertainty in injector delay $(+0.060 \mathrm{~ms},-0.027 \mathrm{~ms})$ measured by Schlieren imaging and the time between CMOS camera frames $(0.046 \mathrm{~ms})$.

Table 3. Variability in ignition delay from repeated points

\begin{tabular}{|l|l|l|l|l|l|}
\hline & Min (ms) & Max (ms) & Mean $(\mathrm{ms})$ & Std Dev $(\mathrm{ms})$ & COV \\
\hline $\mathrm{CH}_{4}$ & 0.465 & 0.901 & 0.736 & 0.113 & $15 \%$ \\
\hline $10 \% \mathrm{C}_{2} \mathrm{H}_{6}$ & 0.438 & 0.903 & 0.671 & 0.119 & $18 \%$ \\
\hline $20 \% \mathrm{~N}_{2}$ & 0.453 & 1.172 & 0.833 & 0.204 & $25 \%$ \\
\hline
\end{tabular}

The results indicate that the average ignition delay increases $13 \%$ with the addition of $20 \%$ nitrogen,

and increases by $10 \%$ with the addition of $10 \%$ ethane to the methane fuel. Due to the high shot-to-shot variability in measured ignition delay, statistical analysis of variance (ANOVA) techniques indicate that these differences are not statistically significant. The P-values (probability of the two results being sampled from the same data set) are 0.073 for $\mathrm{N}_{2}$ and 0.085 for $\mathrm{C}_{2} \mathrm{H}_{6}$. For all the ANOVA analyses in the present study, the a-priori decision was made to accept a $5 \%$ probability of making a type-I statistical error (identifying a 
significant difference when one is not present); hence only P-values below 0.05 are considered to identify a statistically significant difference between the means. However, the large run-to-run variability means that the statistical power of the experiments may be too small to detect subtle differences in ignition delay time.

Ethane addition does not significantly affect the range of ignition delay times observed. However, adding nitrogen results in a significant increase in this range. It is interesting to note that the minimum ignition delay times are relatively consistent for all three fuels, but that the longest observed ignition delay increases $30 \%$ with $\mathrm{N}_{2}$ in the fuel. The $20 \% \mathrm{~N}_{2}$ case also has higher variability, as represented by an increase in the coefficient of variation (COV) of the ignition delay from $15 \%$ for pure methane to $25 \%$ for methane/nitrogen blend.

The ignition delay of all three fuels studied is sensitive to the pre-combustion temperature, as shown in Figure 1. For a given fuel, within the run-to-run variability, higher temperatures result in shorter ignition delays. This is expected, as higher temperatures will tend to enhance the rates of the combustion-initiating reactions (Heywood, 1988; Bi and Agrawal, 1998). At temperatures above $1350 \mathrm{~K}$, however, the ignition delay approaches a limiting value as suggested previously (Naber et al. 1994). Under these conditions, it is possible that physical (mixing) limitations are restricting the ignition process, as suggested by Bi and Agrawal (1998). The effect of fuel composition on the ignition delay, shown in Figure 1, is secondary to the effect of temperature. Fuel dilution with $\mathrm{N}_{2}$ has no apparent influence on the ignition delay, over the range of temperatures investigated. Adding $\mathrm{C}_{2} \mathrm{H}_{6}$ to the fuel has no consistent influence on the ignition delay. Although the experimental variability is large and the number of data points is limited, the results suggest that there may be a reduction in ignition delay with ethane addition at lower pre-combustion temperatures. This is the condition where the increased radical generation associated with $\mathrm{C}_{2} \mathrm{H}_{6}$ would be expected to have the greatest effect at enhancing the ignition kinetics. However, there are not sufficient data points to draw any statistically significant conclusions.

\section{Ignition kernel location}

The addition of either ethane or nitrogen to the fuel increases the density of the fuel jet, which results in an increased penetration distance, as suggested by Hill \& Ouellette (1999). However, the increase in density is relatively small ( $15 \%$ for $20 \% \mathrm{~N}_{2}, 9 \%$ for $10 \% \mathrm{C}_{2} \mathrm{H}_{6}$ ), and as penetration length scales with the $1 / 4$ power of the density, the jet penetration distance only increases by approximately $4 \%$ for $20 \% \mathrm{~N}_{2}$ case and $2 \%$ for $10 \% \mathrm{C}_{2} \mathrm{H}_{6}$ case. The location of the ignition kernel, however, will depend more on the mixing rate and 
the local turbulent intensity (tending to diffuse energy and radicals away from the ignition kernels) than on the total penetration length.

Table 4 summarizes $Z_{k}{ }^{*}$, the ignition kernel location relative to the equivalent orifice diameter for the repeated data set at fixed $T_{0}$ and $P_{0}$. Uncertainty in $Z_{k}$ is estimated to be approximately $1 \mathrm{~mm}$ (5 pixel widths) due to camera spatial and temporal resolution. After normalization, the uncertainty in $Z_{\mathrm{K}}{ }^{*}$ is approximately $2 \%$, mainly due to uncertainty in $\mathrm{P}_{\mathrm{o}}$.

Table 4. Variability in $Z_{k}{ }^{*}$ from repeated points

\begin{tabular}{|l|l|l|l|l|l|}
\hline & Min & Max & Mean & Std Dev & COV \\
\hline $\mathrm{CH}_{4}$ & 18 & 54 & 32 & 8 & $26 \%$ \\
\hline $10 \% \mathrm{C}_{2} \mathrm{H}_{6}$ & 19 & 55 & 41 & 11 & $26 \%$ \\
\hline $20 \% \mathrm{~N}_{2}$ & 17 & 69 & 41 & 13 & $31 \%$ \\
\hline
\end{tabular}

With both $\mathrm{C}_{2} \mathrm{H}_{6}$ and $\mathrm{N}_{2}$ addition to the fuel, the ignition kernel moves further downstream; the mean $Z_{k}{ }^{*}$ increases by $28 \%$ in both cases. The results for ethane are generally consistent with the preliminary data presented by Sullivan et al. (2006). Conducting an ANOVA between the pure methane and the fuels containing $\mathrm{N}_{2}$ and $\mathrm{C}_{2} \mathrm{H}_{6}$ indicate that both differences are statistically significant ( $P$-values of 0.011 and 0.003 , respectively). Ethane addition does not affect the variability of $Z_{k}{ }^{*}$, with a COV of $26 \%$ for both fuels; however, $\mathrm{N}_{2}$ addition increases the variability of the location of the ignition event with the COV increasing to $31 \%$. This increase in $Z_{k}{ }^{*}$ is not simply a result of the longer ignition delay, as demonstrated in Figure 2, which shows no significant correlation between $Z_{k}{ }^{*}$ and $t_{d \_ \text {ign }}$ for all three fuels.

For all three fuels studied, ignition kernels are generally not present in the region near the injector orifice, due to the relatively rich mixture in the core of the jet, short residence times, and high turbulent strains on the periphery of the jet. Nor does ignition occur near the jet tip, as this region is characterized by a starting spherical vortex structure with high turbulent strain rates and limited fuel-air mixing. Increasing the density of the fuel tends to shift the ignition kernel location downstream, closer to the jet tip, although the minimum ignition locations were essentially identical for all three fuels.

\section{$\mathrm{NO}_{x}$ Emissions}

Of the combustion by-products of regulatory concern, $\mathrm{NO}_{\mathrm{x}}$ emissions tend to be one of the most sensitive to combustion conditions. Table 5 summarizes the measured $\mathrm{NO}_{\mathrm{x}}$ emissions for the repeated data set at fixed $\mathrm{T}_{\mathrm{o}}$ and $\mathrm{P}_{\mathrm{o}}$ for all three fuels. To facilitate comparison, all of the $\mathrm{NO}_{\mathrm{x}}$ results are normalized by the 
total quantity of energy in the fuel. Error in the normalized $\mathrm{NO}_{\mathrm{x}}$ emissions is estimated at $\sim 5 \%$, mainly due to the uncertainty in the amount of fuel injected per shot.

Table 5. Variability in normalized $\mathrm{NO}_{x}$ emissions from repeated points

\begin{tabular}{|l|l|l|l|l|l|}
\hline & Min $(\mathrm{g} / \mathrm{MJ})$ & Max $(\mathrm{g} / \mathrm{MJ})$ & Mean $(\mathrm{g} / \mathrm{MJ})$ & Std Dev $(\mathrm{g} / \mathrm{MJ})$ & COV \\
\hline $\mathrm{CH}_{4}$ & 0.47 & 1.18 & 0.91 & 0.19 & $21 \%$ \\
\hline $10 \% \mathrm{C}_{2} \mathrm{H}_{6}$ & 0.91 & 1.47 & 1.25 & 0.17 & $13 \%$ \\
\hline $20 \% \mathrm{~N}_{2}$ & 0.09 & 0.62 & 0.33 & 0.16 & $50 \%$ \\
\hline
\end{tabular}

Nitrogen addition results in a significant decrease in $\mathrm{NO}_{\mathrm{x}}$ emissions, with a $64 \%$ decrease in the mean value. Conversely, ethane addition causes a significant increase in $\mathrm{NO}_{\mathrm{x}}$ emissions, with a $38 \%$ increase in the mean value from the baseline methane case. Both these differences are statistically significant, with ANOVA's generating P-values of 0.00 in both cases. The sensitivity to $T_{0}$ for both fuels is shown in Figure 1. While for the $\mathrm{N}_{2}$ case $\mathrm{NO}_{\mathrm{x}}$ emissions are clearly reduced at all temperatures, the observed increase in $\mathrm{NO}_{x}$ with $\mathrm{C}_{2} \mathrm{H}_{6}$ is only readily apparent at the repeated test point. At all other temperatures, there is no clear increase in $\mathrm{NO}_{x}$; and although there are insufficient test points to draw a reliable conclusion, the results suggest that $\mathrm{NO}_{x}$ emissions are not significantly increased by ethane addition at higher combustion temperatures.

The effects of fuel composition on $\mathrm{NO}_{x}$ formation may be attributed to changes in the adiabatic flame temperature $\left(\mathrm{T}_{\mathrm{ad}}\right)$, which strongly influences the dominant thermal NO formation mechanism. We have estimated $T_{a d}$ for different fuel compositions using the chemical equilibrium package GasEQ. Table 6 shows the calculated $\mathrm{T}_{\mathrm{ad}}$ for a stoichiometric reaction and for two different molar air-fuel ratios. Starting from both near-stoichiometric and lean conditions, $\mathrm{N}_{2}$ addition to the fuel further reduces the fuel concentration in the reaction zone, resulting in an adiabatic flame temperature significantly lower than would be expected by simply adding the diluent. Conversely, the adiabatic flame temperature of the methane/ethane blend is significantly higher than that for pure methane fuel, and the equivalence ratio is slightly increased.

Table 6 Adiabatic flame temperatures for different fuels (fuel temperature $300 \mathrm{~K}$, oxidizer temperature $1300 \mathrm{~K}$, pressure $30 \mathrm{bar}$ )

\begin{tabular}{|l|c|c|c|c|c|c|}
\hline \multirow{2}{*}{} & \multicolumn{2}{|c|}{ Stoichiometric $(\phi=1)$} & \multicolumn{2}{c|}{ Air/Fuel=10 $(\mathrm{mol} / \mathrm{mol})$} & \multicolumn{2}{c|}{ Air/Fuel=20 (mol/mol) } \\
\cline { 2 - 7 } & Air/Fuel $(\mathrm{mol} / \mathrm{mol})$ & $\mathrm{T}_{\mathrm{ad}}(\mathrm{K})$ & $\phi$ & $\mathrm{T}_{\mathrm{ad}}(\mathrm{K})$ & $\phi$ & $\mathrm{T}_{\mathrm{ad}}(\mathrm{K})$ \\
\hline Methane & 9.5 & 2774 & 0.95 & 2752 & 0.48 & 2204 \\
\hline $10 \%$ Ethane & 10.2 & 2780 & 1.02 & 2786 & 0.51 & 2255 \\
\hline $20 \%$ Nitrogen & 7.6 & 2745 & 0.76 & 2559 & 0.38 & 2028 \\
\hline
\end{tabular}

In general, the stochastic nature of the ignition and combustion processes of the developing turbulent jet are likely responsible for the wide variation in autoignition and $\mathrm{NO}_{\mathrm{x}}$ emissions. Various 
realizations of the jet starting and penetration process yield different strain histories and mixture fraction histories, some of which provide more favourable conditions for ignition kernel formation than others. Beyond the random nature of the developing turbulent jet, macro-scale influences from the injector and initial temperature field may play a role in the variability in ignition timing. In the present study neither is measured directly; this remains a subject for further investigation.

\section{SIMULATION RESULTS}

The CSE-TGLDM method discussed earlier has been used to simulate the auto-ignition of methane jets with varying compositions. The simulated conditions are equivalent to those used in the shock tube, with the gaseous fuel jet injected at 120 bar and $300 \mathrm{~K}$ through a $0.28 \mathrm{~mm}$ diameter nozzle into quiescent air at 30 bar and at temperatures between 1200 and $1400 \mathrm{~K}$. Ignition delay is defined in a manner equivalent to that of the shock tube experiments discussed previously. In comparing the modelling and experimental results, it should be remembered that the modelling does not attempt to account for the stochastic variability in the flow field and the corresponding effects on the physical component of the ignition delay time. Nor can it provide any insight into the influence of fuel composition on ignition stability.

To analyze the effects of different additives on the auto-ignition process, the predicted ignition delay of the three fuel compositions are compared. As Figure 3 shows, the model predicts a modest reduction in ignition delay time with the methane-ethane jet. Conversely, nitrogen addition to the fuel slightly increases ignition delay. At high pre-combustion temperatures, the model predicts that fuel composition has no effect on ignition delay time.

Changing fuel composition also affects the mixing between the jet and the oxidizer. Given the same injection parameters, a greater mass is injected when $\mathrm{C}_{2} \mathrm{H}_{6}$ or $\mathrm{N}_{2}$ is added to the fuel because of the higher molecular weight of these species. As a result, the gaseous jet momentum is increased and mixing is enhanced. As a demonstration, the jet stoichiometric surfaces are presented for the pure methane and methane with additives jets in Figure 4. The stoichiometric contours are shown during the injection process $(t=0.9 \mathrm{~ms})$ and just after the end of injection $(t=1.1 \mathrm{~ms})$. The figures show that the methane/additive jets penetrate further than the pure methane jet. When the contours at the same mixture fraction are compared for the three jets, the penetration of the methane/nitrogen and methane/ethane jets are similar, and are both longer than the pure methane case. Interestingly, the equivalent diameter of the jet, on the stoichiometric surface, for a given downstream location $(x)$ of the methane/nitrogen jet is significantly smaller than the 
methane/ethane and pure methane cases. This comparison is of interest because of the possible application in compression ignition engines, where pilot fuel injection can be used to ignite the gas near the tip of the main jet and the shape of the jet thus affects the engine performance.

Altogether, the effects of additives are a result of the competition between chemical kinetics and mixing. The changes in ignition delay are related to the percentage and properties of the additives and the pre-combustion conditions. At low pre-combustion temperatures, ignition delay is mainly affected by changes in chemical kinetics, where ethane accelerates ignition and nitrogen retards ignition. At high temperatures, the formation of the ignition kernel seems to be mainly limited by the mixing of fuel and air, where the chemical kinetics are 'fast enough' and the changes in mixing caused by additives are not sufficiently large to make any noticeable difference because of the relatively short time for mixing prior to ignition.

\section{ENGINE RESULTS}

The addition of either nitrogen or ethane to the fuel has a significant influence on the combustion process and especially on the emissions of a pilot ignition, direct-injection of natural gas engine. These results have been published in more detail elsewhere (McTaggart-Cowan, 2006; McTaggart-Cowan et al. 2008). The material presented here will focus on the ignition, early combustion stability, and $\mathrm{NO}_{\mathrm{x}}$ formation influences of fuel composition, which will allow direct comparison with the shock tube and modeling work presented above.

Adding $\mathrm{N}_{2}$ or $\mathrm{C}_{2} \mathrm{H}_{6}$ to the fuel has a small, but significant, impact on the heat-release rate. Figure 5 shows the IHR for all three fuel blends for a gaseous fuel start-of-injection timing of approximately $10^{\circ} \mathrm{CA}$ before top-dead-center (TDC). The figure demonstrates that, in general, the bulk of the combustion occurs at a similar rate, with the greatest difference being a slower end-of-combustion period for the $20 \% \mathrm{~N}_{2}$ case; this can be attributed to the lower fuel energy density, and hence longer injection duration. Figure 5 also demonstrates that, in the initial gaseous-fuel ignition phase (shown in the right-hand plot) the ignition event occurs earlier for both $20 \% \mathrm{~N}_{2}$ and $10 \% \mathrm{C}_{2} \mathrm{H}_{6}$ cases. The resulting initial combustion phase, which will involve a partially-premixed mixture of fuel and oxidizer, is slower in both these cases. This is a result of a smaller quantity of fuel having pre-mixed to an ignitable stoichiometry before the initial ignition occurs, resulting in a longer (more mixing-controlled) combustion event.

The earlier ignition of both $20 \% \mathrm{~N}_{2}$ and $10 \% \mathrm{C}_{2} \mathrm{H}_{6}$ cases is consistent at all combustion timings, as shown in Figure 6. As discussed earlier, it is very difficult to accurately and repeatably differentiate the start- 
of-combustion of the gaseous fuel based solely on the heat-release rate. As a result, the $10 \% \mathrm{IHR}$ point is taken as a reliable indicator of the point at which gaseous-fuel combustion is progressing. As Figure 5 suggests, the $10 \%$ IHR point is typically found at the point where the HRR starts to increase rapidly, due to sustained combustion of the gaseous fuel. It is also sufficiently larger than the maximum pilot contribution ( $5 \%$ of the total energy) that it can be reliably assumed that it is the gaseous fuel that is burning. The delay between the commanded gas start of injection (GSOI) and the $10 \% \mathrm{IHR}$ point is shown in Figure 6; the variability (on a cycle-by-cycle basis) of this value is also shown. The plots clearly indicate that both the $20 \%$ $\mathrm{N}_{2}$ and $10 \% \mathrm{C}_{2} \mathrm{H}_{6}$ cases have significantly shorter and less variable combustion delay periods.

The combustion delay and ignition processes have a substantial impact on pollutant formation; however, given the complexity of the combustion and pollutant formation processes, it is very difficult to identify causal relationships between the early phases of the combustion event and measured engine-out pollutant levels. The two emissions that are, generally, more sensitive to variations in the ignition process are $\mathrm{NO}_{\mathrm{x}}$ and total hydrocarbons (tHC - predominantly unburned methane). The emissions of these species, normalized by the total quantity of energy in the fuel, are also shown in Figure 6. The $\mathrm{NO}_{\mathrm{x}}$ emissions show very little sensitivity to fuel composition; the effect of combustion timing is much larger, due to the significant effect of timing on the reaction zone temperature. The tHC emissions are more sensitive to fuel composition; this may be a result of the shorter ignition delay time leading to a reduction in the amount of fuel which has mixed beyond a combustible level prior to ignition occurring. It may also be a result of variations in chemical kinetics or in the later stages of the combustion event; it is not possible to conclusively identify the fundamental source of the emissions.

\section{COMBUSTION SYSTEM INTERPRETATION}

As the above sections demonstrate, there are substantial differences in the influences of gaseous fuel composition on the results from the two experimental non-premixed combustion systems. However, both the similarities and the differences provide substantial insight into the non-premixed combustion of natural gas under conditions representative of those in an internal combustion engine.

Neither nitrogen nor ethane addition to the fuel has a statistically significant effect on a non-premixed gaseous jet's auto-ignition delay time (Table 3); however, if an ignition source is provided, the ignition delay time can be reduced (Figure 6). The numerical modelling suggests that the auto-ignition delay time of a gaseous jet will be reduced through the addition of ethane to the fuel, due to chemical kinetic enhancement. 
Conversely, fuel dilution with nitrogen increases the concentration of inert species in the gaseous jet, which absorb some of the energy released in the pre-combustion reactions and hence retards the ignition process. Similar trends are observed in the shock tube results, although the magnitudes of these differences are relatively small, compared to the experimental variability in the shock tube facility. As a result of this variability, and the small magnitude of the differences predicted by the simulations, it is not surprising that no statistically significant differences are observed in the shock-tube results. Both modelling and shock tube results also suggest that, at higher temperatures, the influence of the fuel composition on ignition delay is eliminated. The engine results demonstrate a larger magnitude change in ignition delay than would be predicted from the fundamental studies; they also suggest that nitrogen addition reduces ignition delay, which is the opposite of the fundamental combustion study results. This highlights that the engine ignition process differs substantially from the auto-ignition of a gaseous jet.

The shock tube study indicates that the spatial location of the ignition is sensitive to the fuel composition. Specifically, ignition occurs further downstream on the gas jet periphery with either ethane or nitrogen addition (Table 4). This coincides with the numerical results, which demonstrate that, for a surface of equivalent stoichiometry at an equivalent time after the start of injection, the jet will penetrate further with either ethane or nitrogen in the gaseous fuel. As a result, the areas of ignitable stoichiometry are located further downstream a given time after the start-of-injection, even though the ignition delay time is not significantly affected. This result explains the shorter ignition delay time observed in the pilot-ignited engine configuration, in that the jet containing either nitrogen or ethane penetrates further into the combustion chamber a given time after the start of the injection process. Thus, ignitable regions of the gas jet are approaching the diesel pilot reaction zone sooner, leading to a shorter pilot-ignited delay time. These results demonstrate that, in a gaseous-fuelled direct-injection engine with pilot ignition, the spatial and temporal relationships between the gas jet and the ignition source are pivotal in controlling the timing of the ignition and the stability of the early-combustion processes.

The temporal and spatial variability of the auto-ignition event in general is increased with the addition of either ethane or nitrogen to the fuel. Conversely, the pilot-ignited combustion event is significantly stabilized by the addition of either species. This suggests that the earlier arrival of the gaseous jet in the pilot-reaction zone, where more reactive radicals and a higher temperature may remain from the diesel pilot reactions, will result in a more reliable ignition process. 
Fuel composition has no significant effect on $\mathrm{NO}_{\mathrm{x}}$ emissions from the direct-injection of natural gas engine. The shock tube, however, sees substantial effects, especially with $\mathrm{N}_{2}$ in the fuel. The low $\mathrm{NO}_{x}$ generation in the shock tube is a result of lower combustion temperatures, as suggested from the adiabatic flame temperature calculations. However, the principal change in flame temperature is due to changes in reaction zone fuel-oxidizer stoichiometry, rather than fuel composition, as shown in Table 6. The fact that fuel composition has no significant influence on the engine-out $\mathrm{NO}_{\mathrm{x}}$ suggests that the stoichiometry of the reaction zone in the engine is not changing substantially. These results indicate that substantially reducing the local equivalence ratio prior to ignition could be a method to control $\mathrm{NO}_{\mathrm{x}}$ emissions in a pilot-ignited nonpremixed combustion event. However, this effect would need to be carefully controlled to avoid having a larger quantity of premixed fuel ready to burn once ignition occurs; a large premixed combustion phase can lead to higher combustion temperatures and longer residence times for the early-burned fuel, resulting in higher overall $\mathrm{NO}_{\mathrm{x}}$ emissions. One potential technique to avoid this could be the use of reduced injection rates for the early-injected fuels.

\section{CONCLUSIONS/SUMMARY}

1) Neither ethane nor nitrogen addition to the fuel significantly affect the auto-ignition delay of a transient methane jet. These results are supported by simulation, which suggests that differences in ignition delay would be smaller than the experimental uncertainty. However, either fuel additive reduces the ignition delay in a pilot-ignited non-premixed engine by shifting the most ignitable regions of the jet further downstream, resulting in earlier ignition by the pilot flame. This highlights the importance of the spatial and temporal location of the pilot flame for igniting the gaseous jet.

2) Combustion simulations suggest that the primary effect of $N_{2}$ is thermal, as the higher thermal mass of the fuel reduces the rate of temperature rise during the early phases of the reaction event. The principal effect of ethane is to change the chemical kinetics, influencing the rate of formation (and destruction) of critical radicals in the early reaction event.

3) Nitrogen dilution reduces the combustion temperature, lowering the $\mathrm{NO}_{\mathrm{x}}$ formation rate for an equivalent fuel-air stoichiometry. The dilution also affects the fuel-air stoichiometry, further influencing the combustion temperature. In an auto-igniting jet, these effects combine to substantially reduce $\mathrm{NO}_{\mathrm{x}}$ emissions. For the pilot-ignited case, however, no significant effect on $\mathrm{NO}_{x}$ emissions is observed. 
4) Ethane addition to the fuel increases the flame temperature, resulting in an increase in $\mathrm{NO}_{\mathrm{x}}$ emissions for the auto-igniting natural gas jet. Any such increases are smaller than the experimental uncertainty in the engine experiments; they may also be offset by changes in reaction zone stoichiometry in the pilot-ignited combustion regime.

5) Nitrogen dilution increases the variability of auto-ignition of a gaseous jet. However, if a stable ignition source is provided, the variability in the non-premixed combustion event is reduced by either adding nitrogen or ethane to the fuel. This suggests that pilot ignition can reliably ignite fuels of varying compositions that might not auto-ignite in a spatially- or temporally-repeatable manner.

\section{REFERENCES}

Jin, B. (2007) Conditional Source-Term Estimation Methods for Reacting Flows. Ph.D. Thesis. University of British Columbia, Vancouver, Canada.

Bi, H. and A.K. Agrawal. (1998) Study of Autoignition of Natural Gas in Diesel Environments Using Computational Fluid Dynamics with Detailed Chemical Kinetics. Combustion and Flame, 113. Pp. 289-302.

Bushe, W.K. and H. Steiner. (1999) Conditional moment closure for large eddy simulation of nonpremixed turbulent reacting flows. Physics of Fluids. 11. 1896-1906.

Crookes, R.J. (2006) Comparitive Bio-Fuel Performance in Internal Combustion Engines. Biomass \& Bioenergy. 30. Pp. 461-468.

Feese, J.J. and S.R. Turns. (1998) Nitric Oxide Emissions from Laminar Diffusion Flames: Effects of Air-Side versus Fuel-Side Diluent Addition. Combustion and Flame. 113. Pp. 66-78.

Fotache, C.G., T.G. Kreutz and C.K. Law. (1997) Ignition of Counterflowing Methane versus Heater Air under Reduced and Elevated Pressures. Combustion and Flame. 108. Pp. 442-470.

Gulder, O.L. (1995) Effects of Oxygen on Soot Formation in Methane, Propane, and n-Butane Diffusion Flames. Combustion and Flame. 101. Pp. 302-310.

Heywood, J.B. (1988) Internal Combustion Engine Fundamentals, McGraw-Hill, New York.

Hill, P. G., and P. Ouellette. (1999) Transient Turbulent Gaseous Fuel Jets for Diesel Engines. ASME Journal of Fluids Engineering. 121. Pp. 93-101

Hill, P.G. and G.P. McTaggart-Cowan. (2005) Nitrogen Oxide Production in a Diesel Engine Fuelled with Natural Gas. SAE Technical Paper 2005-01-1927.

Hiltner, J., R. Agama, F. Mauss, B. Johansson and M. Christensen. (2003) Homogeneous Charge Compression Ignition Operation With Natural Gas: Fuel Composition Implications. ASME Journal of Engineering for Gas Turbines and Power. 125. Pp. 837-844.

Huang, J. and W.K. Bushe. (2007) Simulation of an igniting methane jet using Conditional Source-term Estimation with a Trajectory Generated Low-Dimensional Manifold. Combustion Theory and Modelling. 11(6). Pp. 977-1008. 
Huang, J. and W.K. Bushe. (2006) Experimental and Kinetic Study of Autoignition in Methane/Ethane/Air and Methane/Propane/Air mixtures under Engine-Relevant Conditions. Combustion and Flame. 144. Pp. 74-88.

Huang, J., P.G. Hill, W.K. Bushe and S.R. Munshi. (2004) Shock-Tube Study of Methane Ignition under Engine-Relevant Conditions: Experiments and Modeling. Combustion and Flame. 136(1-2). Pp. 25-42.

Huang, J. (2000) Experimental Shock Tube Study of Ignition Promotion for Methane under Engine Relevant Conditions, M.Sc. Thesis, University of British Columbia, Vancouver, Canada.

Jones, H.L., G.P. McTaggart-Cowan, S.N. Rogak, W.K. Bushe, S.R Munshi, and B.A. Buchholz. (2005) Source Apportionment of Particulate Matter From a Diesel Pilot- Ignited, Natural-Gas-Fueled, Heavy-Duty DI Engine, SAE Technical Paper 2005-01-2149.

Khalil, E.B. and G.A. Karim. (2002) A Kinetic Investigation of the Role of Changes in the Composition of Natural Gas in Engine Applications. ASME Journal of Engineering for Gas Turbines and Power. 124. Pp. 404-411.

Klimenko, A. and R. Bilger. (1999). Conditional moment closure for turbulent combustion. Progress in Energy and Combustion Science. 25(6) 595-687.

Maas, U. and S. B. Pope. (1992) Simplifying chemical kinetics: Intrinsic low dimensional manifolds in composition space. Combustion and Flame. 88. Pp. 239-246.

McTaggart-Cowan, G.P. (2006) "Pollutant Formation in a Gaseous-Fuelled, Direct-Injection Engine". Ph.D. Thesis. University of British Columbia, Vancouver, Canada.

McTaggart-Cowan, G.P., W.K. Bushe, P.G. Hill and S.R. Munshi. (2003) A Supercharged Single-Cylinder Heavy-Duty Engine for High Pressure Direct Injection of Natural Gas. International Journal of Engine Research. 4(4). Pp. 315-330.

McTaggart-Cowan, G.P., S.N. Rogak, P.G. Hill, S.R. Munshi and W.K. Bushe. (2008) The Effects of Fuel Dilution in a Direct Injection of Natural Gas Engine. Proceedings of the Institution of Mechanical Engineers Part D - Journal of Automobile Engineering. 222. Pp. 241-254.

Naber, J. D., Siebers, D. L., Julio, S. S. Westbrook C. K., (1994) Effects of Natural Gas Composition on Ignition Delay under Diesel Conditions. Combustion and Flame. 99. Pp.192-200.

Nellen, C. and K. Boulouchos. (2000) Natural Gas Engines for Cogeneration: Highest Efficiency and NearZero Emissions through Turbocharging, EGR and 3-Way Catalytic Converter. SAE Technical Paper 200001-2825.

OpenFOAM program website. Available from: www.opencfd.co.uk/openfoam/. Last accessed 12-04-08.

Richards, G.A., M.M. McMillian, R.S. Gemmen, W.A. Rogers and S.R. Cully. (2001) Issues for LowEmission, Fuel-Flexible Power Systems. Progress in Energy and Combustion Science. 27. Pp. 141-169.

Rubas, P. J., M.A. Paul, G.C. Martin, R.E. Coverdill, R.P. Lucht, J.E. Peters, and K.A. DelVecchio. (1998) Methane Jet Penetration in a Direct-Injection Natural Gas Engine. SAE Technical Paper 980143.

Steiner, H. and W. K. Bushe. (2001) Large Eddy Simulation of a Turbulent Reacting Jet with Conditional Source-Term Estimation. Physics of Fluids. 13. Pp. 754-769.

Sullivan G.D., Huang, J., Wang, T.X., Bushe, W.K., and Rogak, S.N. (2005) Emissions Variability in Gaseous Fuel Direct Injection Compression Ignition Combustion. SAE Technical Paper 2005-01-0917.

Sullivan, G.D., Huang J., Bushe, W.K., and Rogak, S.N. (2006) Autoignition of Transient Turbulent Gaseous Fuel Jets at High Pressure. SAE Technical Paper 2006-01-3432. 
Wang, M., J. Huang and W. K. Bushe. (2006) Simulation of a turbulent nonpremixed flame using conditional source-term estimation with trajectory generated low-dimensional manifold. $31^{\text {st }}$ Symposium (International) on Combustion, The Combustion Institute. Pp. 1701-1709.

Wu, N. (2007) Autoignition and Emission Characteristics of Gaseous Fuel Direct Injection Compression Ignition Combustion. Ph.D. Thesis. University of British Columbia. Vancouver, Canada.

Wu, N., W.K. Bushe, and M.H. Davy. (2007) Autoignition and Emission Characteristics of Gaseous Fuel Direct Injection Compression Ignition Combustion. SAE Technical Paper 2007-01-0131.

Wu, N., Davy, M.H., and Bushe, W.K. (2006) "Ignition and Emission Characteristics of Methane Direct Injection Compression Ignition Combustion," Proceedings of Combustion Institute (Canadian Section) Spring Technical Meeting, Waterloo, ON, Canada. 


\section{FIGURES}
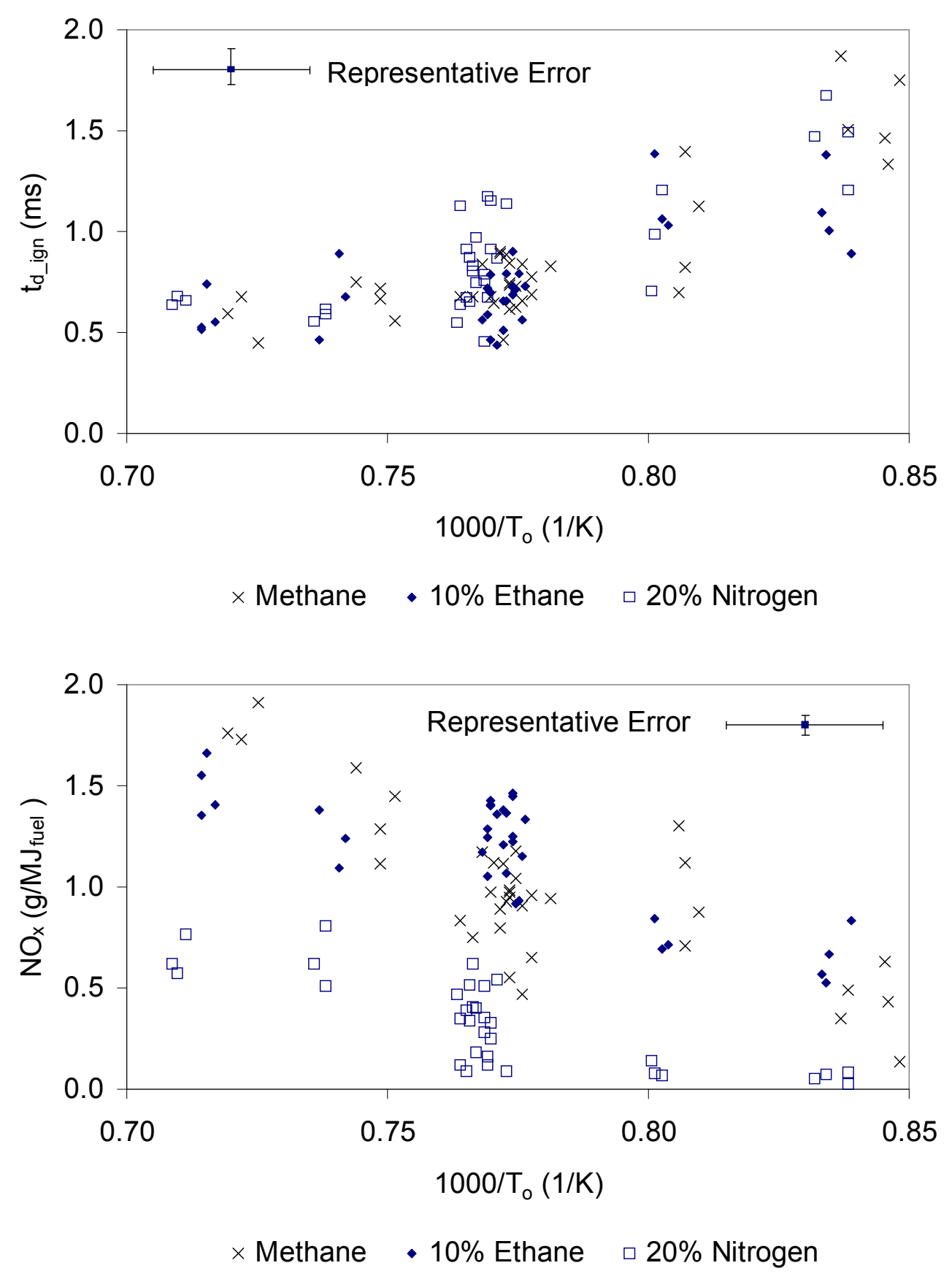

Fig. 1 - Effect of oxidizer temperature on ignition delay ( $t_{d}$ ign, top) and $\mathrm{NO}_{\mathrm{x}}$ emissions (bottom, normalized by energy content of fuel) 


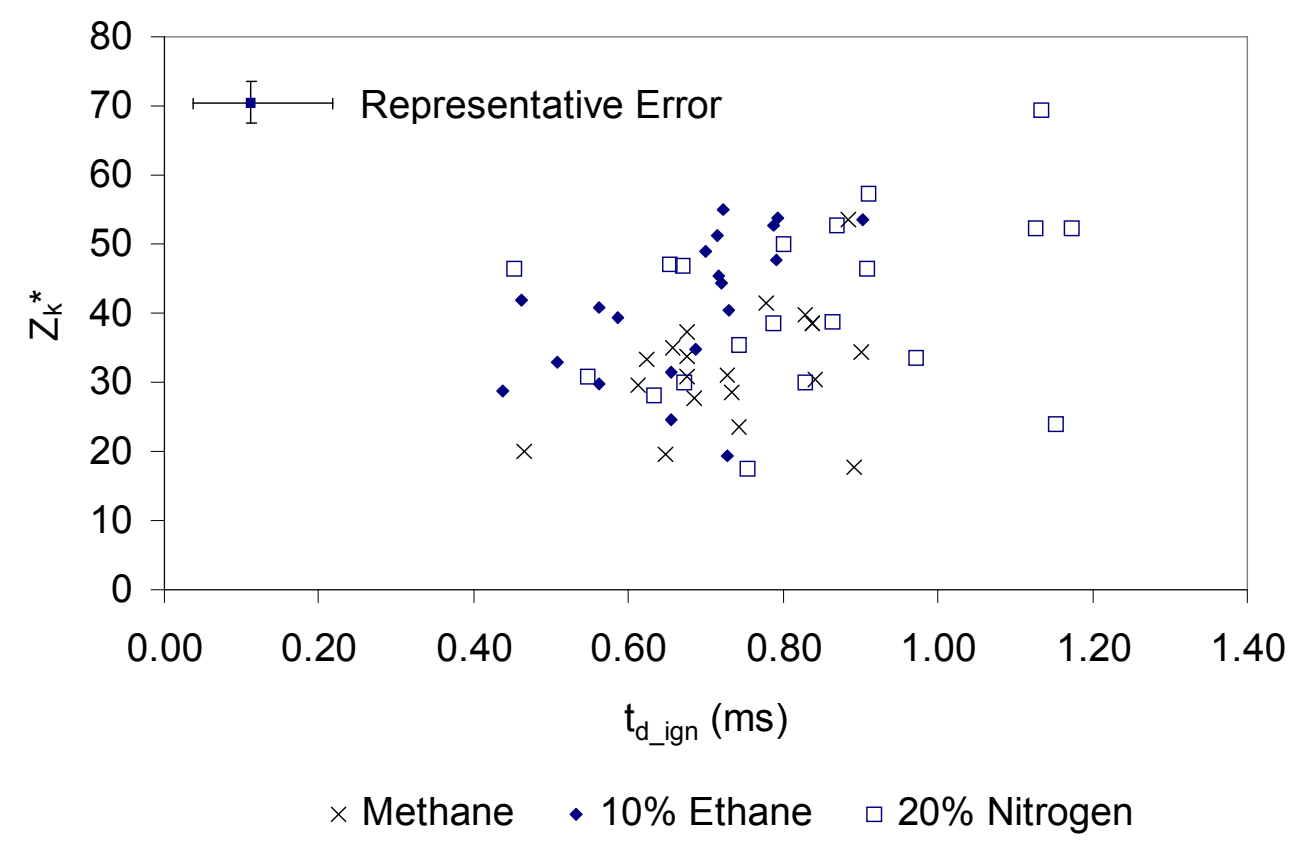

Fig. 2 - Normalized penetration length, $Z_{k}{ }^{*}$, as a function of ignition delay time for all three fuels.

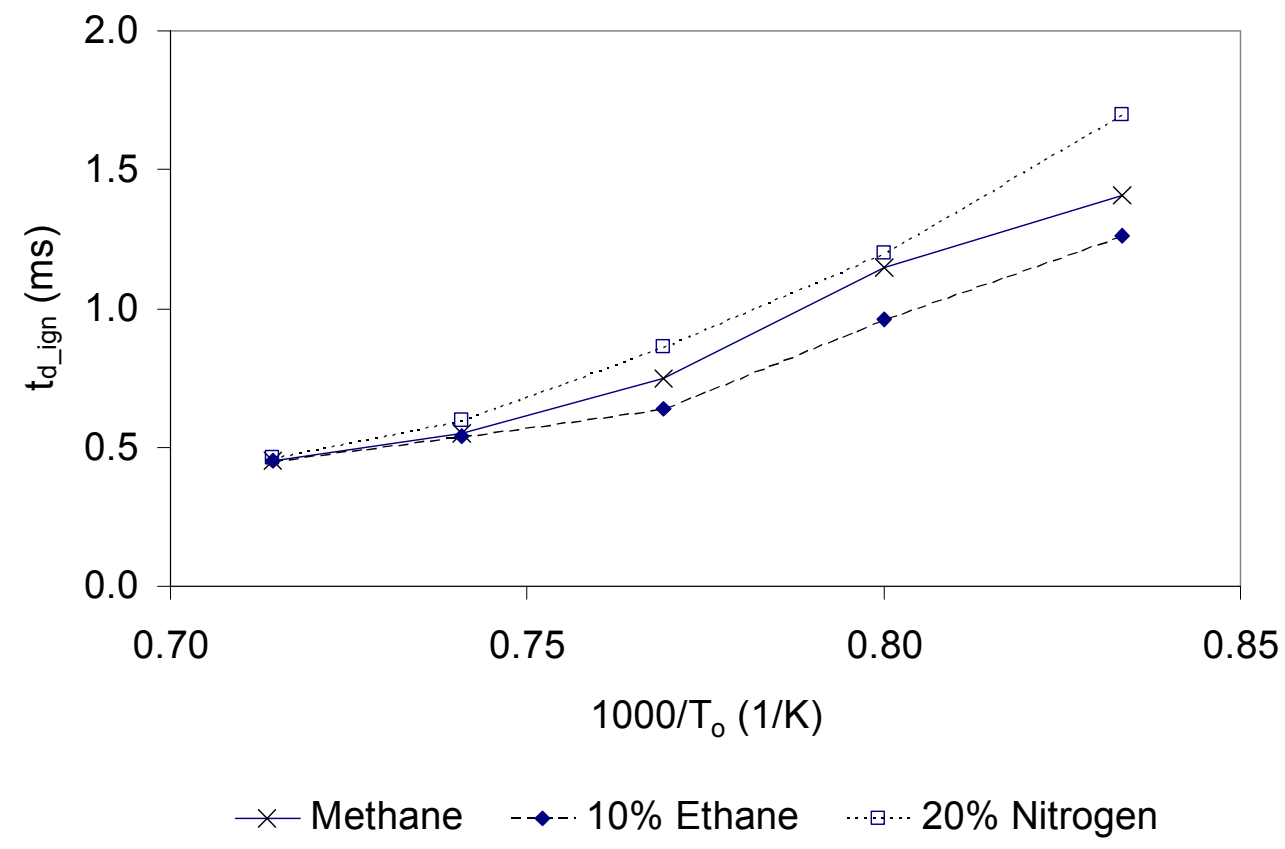

Fig. 3 - Effect of fuel composition on ignition delay predicted using CSE-TGLDM modelling. 


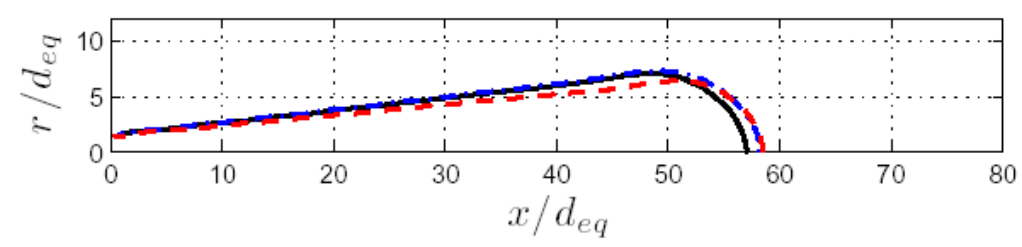

(a) $\mathrm{t}=0.9 \mathrm{~ms}$

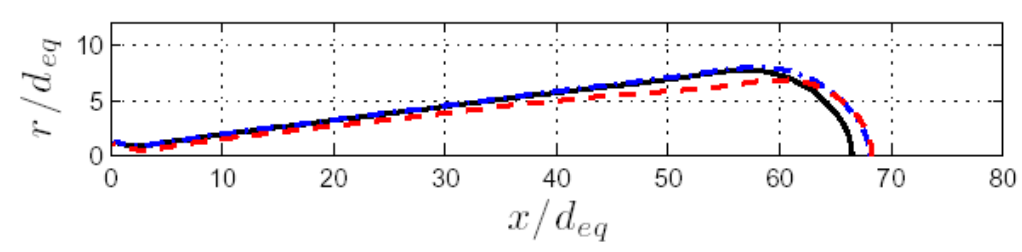

(b) $\mathrm{t}=1.1 \mathrm{~ms}$

Fig. 4 - Effect of fuel composition on stoichiometric contours of gaseous jet. (a): prior to end of injection, (b): post injection. $\mathrm{CH}_{4}$ : solid, black; $20 \% \mathrm{~N}_{2}$ : dashed blue; $10 \% \mathrm{C}_{2} \mathrm{H}_{6}$ : dashed red. $\mathrm{r} / \mathrm{d}_{\mathrm{eq}}$ is the jet radius normalized by the effective nozzle diameter.
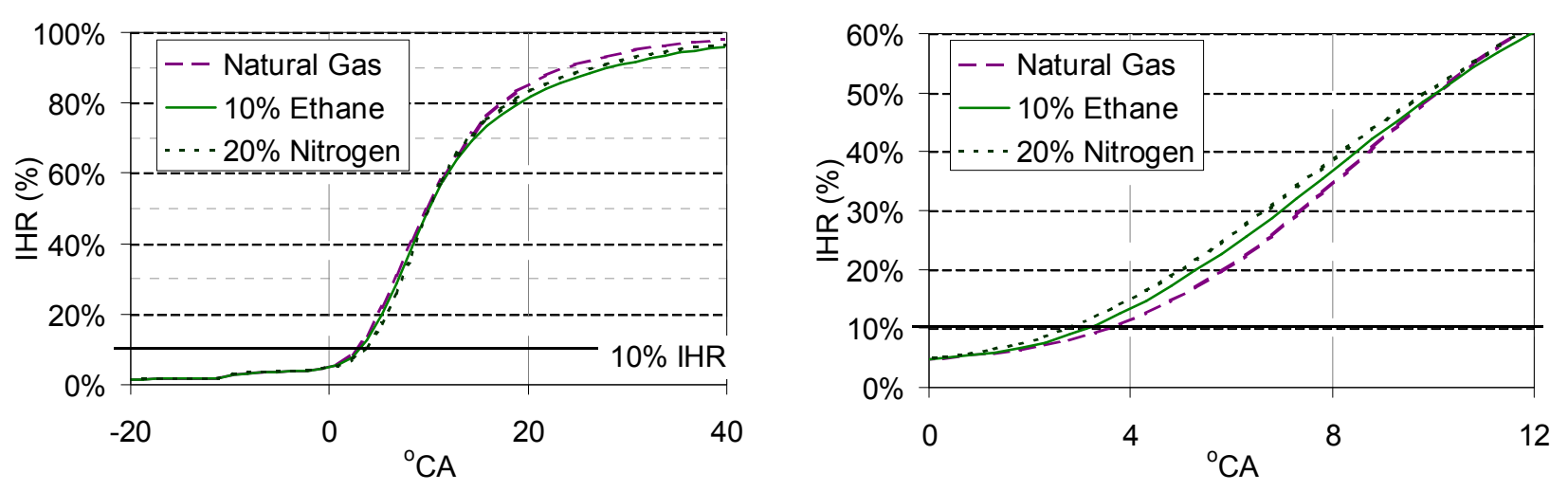

Fig. 5 - Effect of fuel composition on integrated heat release rate for the pilot-ignited engine. Plots are average of 50 cycles for each test point shown. Timing adjusted for $50 \%$ IHR at $10^{\circ} \mathrm{CA}$. Gas start of injection timing was $-10.4^{\circ} \mathrm{CA}$ for natural gas, $-10.5^{\circ} \mathrm{CA}$ for $10 \% \mathrm{C}_{2} \mathrm{H}_{6}$ and $-10.8^{\circ} \mathrm{CA}$ for $20 \% \mathrm{~N}_{2}$. 

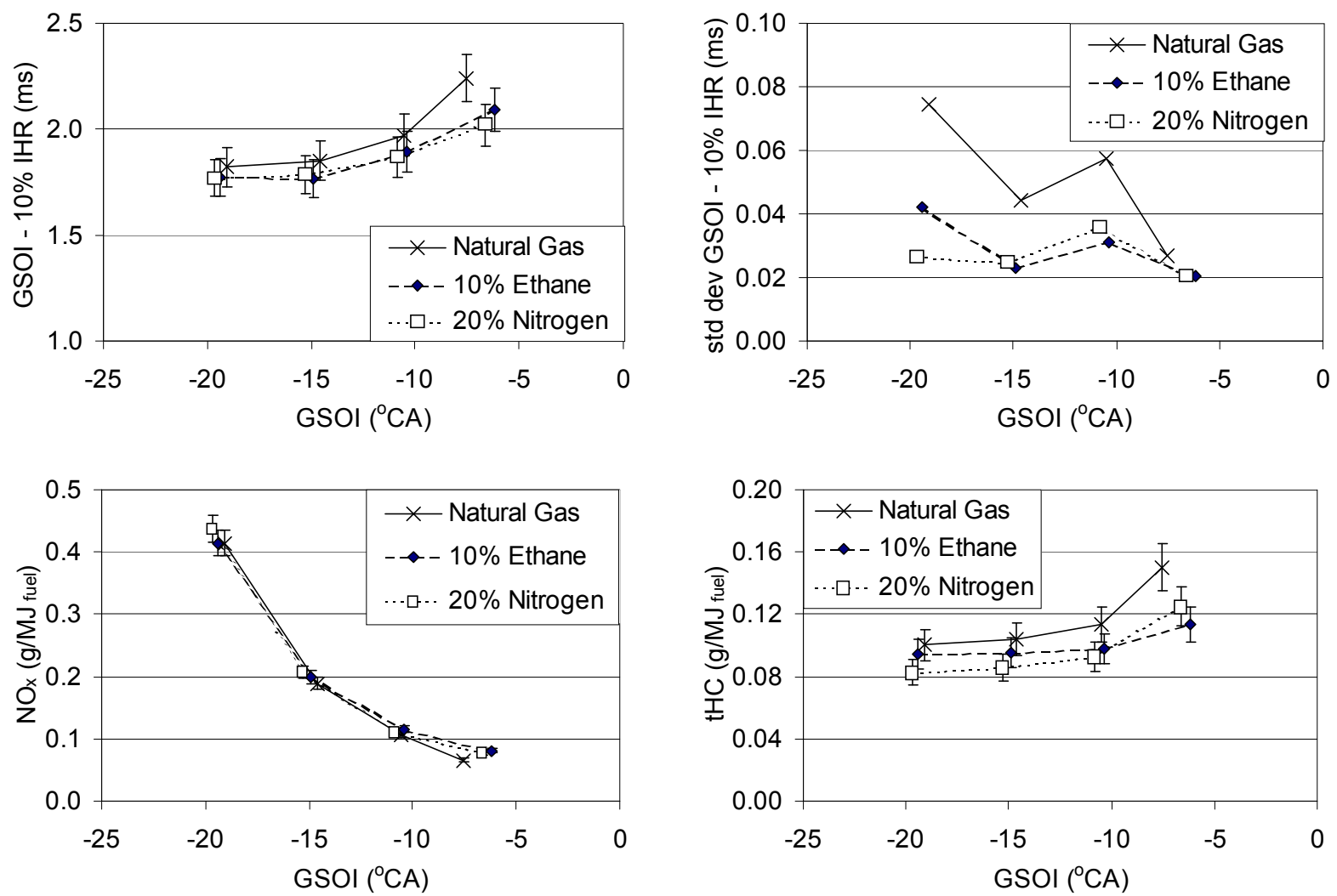

Fig. 6 - Effect of fuel composition on ignition delay and emissions as a function of start-of-injection timing. Ignition delay defined based on integrated heat release, stability on the cycle-to-cycle variability in the heat release rate. Emissions normalized by fuel energy content. Error bars represent $95 \% \mathrm{Cl}$ for repeated test points (minimum 3 for each fuel and timing condition). 